\title{
Prevalence of dental caries in Pakistan: a systematic review and meta-analysis
}

\author{
Ammar Ahmed Siddiqui ${ }^{1 *}$ (D) Freah Alshammary², Mushir Mulla ${ }^{3}$, Saad M. Al-Zubaidi ${ }^{4}$, Eman Afroze ${ }^{5}$, \\ Junaid Amin ${ }^{6}$, Salman Amin ${ }^{7}$, Sameer Shaikh ${ }^{8}$, Ahmed A. Madfa ${ }^{4}$ and Mohammad Khursheed Alam ${ }^{9}$
}

\begin{abstract}
Background: Optimum oral health is impossible to achieve without managing dental caries. The first step to manage dental caries at a community level is to know its prevalence and trend. Unfortunately, the prevalence of dental caries at the national/regional level is not known in many developing countries. Pakistan is no exception. The present meta-analysis was planned to document the prevalence of dental caries at the national, as well as regional level. This paper will serve as a baseline for making future health policies, and health promotion activities in the country.
\end{abstract}

Methods: Literature was searched through various databases, such as PubMed, SCOPUS, and Web of science using: "Prevalence", "Dental Caries", "Dental Decay" and "Severity" as keywords. Any study that reported the prevalence of dental caries, and was conducted in the Pakistani population was included. Thirty studies fulfilled the inclusion criteria. Quality assessment of all the included studies was performed using Joanna Briggs Institute (JBI) critical appraisal checklist for prevalence studies. MedCalc software was used to analyze the data.

Results: In total 27,878 subjects were included in a meta-analysis from 30 studies. The prevalence estimate of dental caries at the national level was 56.62\% (95\% Cl: 49.54 to 63.57). The $\mathrm{I}^{2}$ value was $99.07 \%$ (95\% Cl: 98.94 to 99.18), $\left(1^{2}>75 \%\right)$ indicating heterogeneity, hence pooled proportion was reported using a random-effect model. The prevalence estimate of dental caries in Sindh was 58.946\% (95\% Cl: 43.796 to 73.274), and in Punjab, it was 55.445\% (95\% Cl: 44.174 to 66.44), whilst in Baluchistan and KPK combined was 51.168\% (95\% Cl: 22.930 to 79.004).

Conclusion: Based on the existing data nearly $60 \%$ of the Pakistani population have dental caries. The proportion is almost the same in all provinces. Most of the included studies were found to be of high risk.

Keywords: Dental caries, Dental Decay, Prevalence, Pakistan

\section{Background}

Oral health is a fundamental component of general health and wellbeing. Among various oral diseases, dental caries continues to affect a large number of populations around the globe even though tremendous attempts to raise awareness have been made but still the trend is on the higher side. Dental caries is recognized as a disease of ancient times. It may affect anyone, irrespective

\footnotetext{
*Correspondence: Ammarqta2002@hotmail.com

${ }^{1}$ Department of Community Dentistry, College of Dentistry, Bakhtawar

Amin Medical and Dental College, Multan, Pakistan

Full list of author information is available at the end of the article
}

of ethnicity, age, gender, or socioeconomic status. Management of dental caries nowadays largely depends upon its risk assessment hence it is very important to map out its prevalence in any given population [1-4]. According to the World Health Organization (WHO), dental caries remains a major problem for almost every country in the world. There are many definitions of dental caries [5]. However, it is largely accepted as a multifactorial disease initiated by interactions between fermentable carbohydrates, acidogenic bacteria, and numerous host factors, comprising saliva [6,7]. The principal cause of caries is the acid development of dietary carbohydrates that 
are fermented by bacteria in saliva and plaque. Possible cariogenic bacteria are usually found in relatively small amounts in healthy saliva and plaque. However, there will be a proliferation of acid-tolerant bacteria in some biological and environmental disorders, such as increased frequency of fermentable carbohydrate consumption, low $\mathrm{pH}$ conditions $[8,9]$.

Dental caries is a well-known burden on health. Untreated carious lesions can be painful and may lead to functional limitation, as well as disability $[10,11]$. While dental caries is mostly preventable, the occurrence of dental caries amongst adults is high, affecting almost 35\% of the world's population, making it the most predominant health condition around the world [12]. Dental caries, along with periodontal diseases are a well-known cause of tooth loss, and in some cases even edentulism causing major functional limitation, and impairment [13-15]. As a result, dental caries has long been a worldwide burden on oral health [5]. Not only does it affect oral health, it too harms the quality of life and overall health, particularly in low-income countries [16]. According to the WHO, $60-90 \%$ of children are affected by dental caries [17]. Dental caries affects all age groups, although children are affected to a greater extent than adults. To solve this dilemma, part of the solution is to accurately estimate the current burden in a given geographical location and prepare for robust dental education/health promotion programs. Data on the prevalence of caries is maintained in the WHO Country Area Profile Program database. There are, however, a few limitations: data for all age groups and all WHO countries are not available; and if data is available it is not regularly updated.

The extent of disease distribution offers a unique context for planning strategies and designing public health policies. A systematic review and meta-analysis are one of the most vital research methods for obtaining an accurate estimation of disease indicators in a society. In this study, a meta-analysis was planned to deliver evidence-based information based on which suitable health care strategies can be established to get a whole representation of the situation of dental caries amongst the Pakistani population.

Based on our knowledge, we did not find any national/ regional level studies or any meta-analyses to report the prevalence of dental caries in Pakistan's general population. Therefore, this systematic review and meta-analysis were conducted to estimate the proportion of dental caries in the Pakistani population by using data from already published studies.

\section{Methods}

\section{Search strategy}

Literature in the English language was searched from January 1970 to June 2020 primarily from PubMed,
Scopus, and Web of science using the following MESH Keywords: "Prevalence", "Dental Caries", "Dental Decay" and "Severity". Additional studies were sought from gray literature google scholar, and researchgate. Besides, we also explored the reference lists of identified articles to find further relevant studies. Literature was searched using various search strategies such as prevalence, severity, dental caries, and/or prevalence, severity, dental decay, Pakistan and/or dental caries, prevalence, severity, and/or dental caries, severity, prevalence, Pakistan and/ or dental decay, prevalence, severity, and/or dental decay, severity, prevalence, Pakistan.

\section{Inclusion and exclusion criteria}

We included the studies (a) that provided the prevalence of dental caries in the Pakistani population of any sex or age group. We excluded those articles that (a) did not provide the prevalence of dental caries or data from where prevalence cannot be calculated (b) did not publish in English language (c) involved review articles, case reports, book chapters, and letter.

\section{Selection of studies}

The total number of studies found were 9083 that include from PubMed $(n=58)$, Scopus $(n=1071)$, and Web of Science $(n=5903)$. The additional studies found through other sources were $(n=2051)$. The Reference Management Software Package (Endnote X9) was used to check the duplication and 7013 studies were removed. Studies $(n=1569)$ were conducted other than the Pakistani population. The remaining $(\mathrm{n}=501)$ were further screened and finally, $(\mathrm{n}=39)$ studies were selected for full text read. Of those $(n=7)$ articles did not report the prevalence and $(n=2)$ were review articles. Finally, $(n=30)$ studies were matching the objective and were satisfying the inclusion criteria for this meta-analysis and were included (Fig. 1).

\section{Data abstraction}

After doing the initial search, title papers and abstracts of identified articles were explored for relevance and appropriateness to the study question of the present study. The full text of the included studies was obtained. Two fieldbased experts (A.A.S. and E.F) independently worked on duplication and abstraction of data from each study using a standardized form. The information relating to the prevalence of dental caries, sample size, methodology, year of study, and region/ city was recorded.

\section{Data analysis}

The pooled estimate of dental caries in Pakistan was calculated with a $95 \%$ confidence interval $(\mathrm{CI})$ and data was displayed with both random-effects model and 


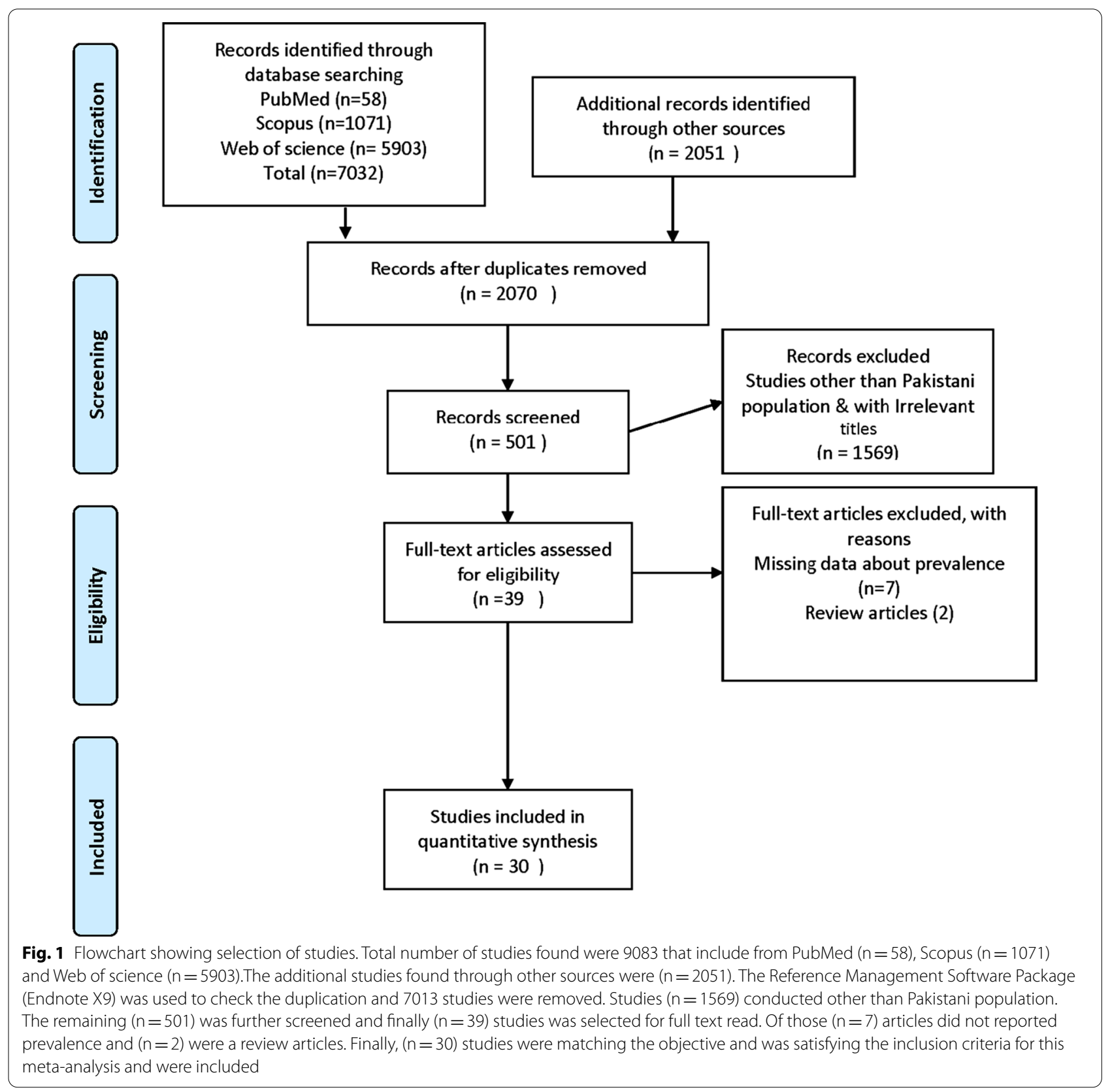

fixed-effects model. The random-effects model of the meta-analysis was considered more appropriate for the current study. In case of substantial heterogeneity among included studies, random-effects model weights study more equally and are considered more appropriate. Cochran's $Q$ test $\left(\chi^{2}\right)$ and the $I^{2}$ statistic were used to calculate the variance between study and heterogeneity in estimates. Cochran $\mathrm{Q}$ was reported as $\mathrm{X}^{2}$ while $\mathrm{I}^{2}$ was reported in the form of percentages. A higher percentage indicated from $\mathrm{I}^{2}$ statistic showed high heterogeneity between estimates of individual studies $\left(\mathrm{I}^{2}<25 \%\right.$ shows low heterogeneity; $30-70 \%=$ moderate heterogeneity and $>75 \%$ shows high heterogeneity). Forest plot was used to present the combined prevalence estimate of dental caries with a $95 \%$ confidence interval (CI). The analysis was conducted by using MedCalc statistical software version 19.5.3.

\section{Quality assessment}

Two independent reviewers (J.A and A.A.M) assessed the quality of included studies. Joanna Briggs Institute (JBI) critical appraisal checklist for prevalence studies was 
used to ascertain the risk of bias in included studies [18]. JBI appraisal checklist is based on 9 items and each item is assessed by scoring (yes $=1),($ no $=0)$, and (unclear or not applicable $=0$ ). The total score obtained of each study was presented as percentages and each study was categorized according to different levels of risk of bias (high risk of bias if $20-50 \%$ items scored yes, moderate risk of bias if $50-80 \%$ items scored yes, and low risk of bias if $80-100 \%$ items scored yes as per JBI checklist) as shown in Table 1 and Fig. 2.

\section{Results}

A total of 27,878 subjects were included in the metaanalysis from 30 studies conducted from 2009 to 2020 on the prevalence of dental carries in Pakistan. Of those studies, 13 (43\%) were from Punjab province, 11 (37\%) from Sindh, 2 studies each from Khyber Pakhtunkhwa (KPK) (7\%) and Baluchistan (7\%), and 2 (7\%) studies from Islamabad. The proportion of selected studies according to the province are classified in (Table 2). In the context of cities, there were 7 studies from Karachi, 4 from Lahore, 3 studies from Hyderabad, 2 studies each from Peshawar, Multan, Islamabad, Quetta, and Rawalpindi while one study each from Sialkot, Bahawalpur, Faisalabad, Bhakkar, Sargodha, and Khairpur city (Table 2).

The prevalence estimate of dental caries in terms of proportion (random effect model) was 56.62\% (95\% CI: 49.54 to 63.57 ). The value of $\mathrm{I}^{2}$ was $99.13 \%$ (95\% CI: 99.02 to 99.23$)$ and $\left(\mathrm{I}^{2}>75 \%\right)$ indicating high heterogeneity among the selected studies and due to this reason, aggregate data of random effect model was selected for meta-analysis. Possible reasons for the high level of heterogeneity could be because of variability in the data reported amongst the studies included in the meta-analysis. Other probable reasons may include a difference in characteristics of participants, as well as the use of the various method of caries detection, or could be because of high publication bias. The mean proportion of random and fixed effects models, along with Cochran's $Q$ value with $P$-value is reported in Table 3.

The prevalence estimate (random effect model) of dental caries in Punjab was 55.445\% (95\% CI: 44.174 to 66.44), in Sindh 58.946\% (95\% CI: 43.796 to 73.274) while in Baluchistan and KPK combined was 51.168\% (95\% CI: 22.930 to 79.004$)$. The prevalence estimate of dental caries in major cities of the countries was as following: Karachi $61.988 \%$ (95\% CI: 45.504 to 77.161 ), Lahore $57.604 \%$ (95\% CI: 47.727 to 67.183 ), while Islamabad and Rawalpindi combined was $57.377 \%$ (95\% CI: 32.642 to 80.287 ). The prevalence estimate of different provinces and cities of Pakistan is shown in Fig. 3.

The proportion estimate was calculated for the primary, mixed and permanent dentition as shown in the additional files (Additional file 1: Tables S1, Additional file 2: S2, Additional file 3: S3 and Additional file 4: Figure S1, Additional file 5: Fig. S2). The prevalence estimate (random effect model) of dental caries in primary dentition was $50.493 \%$ (95\% CI: 43.867 to 57.110 ), in mixed dentition $61.183 \%$ (95\% CI: 43.796 to 73.274 ) while in permanent dentition was $57.184 \%$ (95\% CI: 26.288 to 85.251).

The Forest plot (Fig. 4) is displaying the proportion prevalence of dental caries of each study included in the meta-analysis. The highest prevalence of dental caries was reported by Badar et al. [32] in Bahawalpur while the lowest was reported by Malik et al. [24] in Karachi.

The funnel plot (Fig. 5) shows the effect estimates of the included studies against their measure of precision or size of the studies. The funnel plot is showing asymmetry that is indicating heterogeneity and reporting bias. Moreover, poor methodological design and studies with smaller sample sizes can also lead to asymmetry. Other than the aforementioned reasons, the additional likelihood of asymmetry could be due to language bias (reporting of study in English language only) and citation bias (in which positive outcomes are used more to cite and readily available in scientific databases).

\section{Discussion}

The present study concentrated on all the articles reporting the prevalence of dental caries among a Pakistani population. Thirty studies met the inclusion requirements and were included in this systematic review. Prevalence of dental caries was displayed overall, as well as for primary, mixed and permanent dentition separately. Most of the included studies were of high risk, and some of them did not mention the age groups of the participant or even the method used for detecting dental caries. Within all mentioned limitations to our best knowledge, this is the first meta-analysis on dental caries for the Pakistani population. It will help in providing a proportion estimate of dental caries for the Pakistani population. Additionally, it is indicated that most of the studies on dental caries in a Pakistani population contain a high level of bias. Future studies should be carefully designed.

Even though the current research reported useful information in terms of prevalence and seriousness of dental caries in Pakistani individuals, it is clear that most of the studies were conducted in Punjab and Sindh, with some studies conducted in Baluchistan, KPK, and Islamabad. The present meta-analysis, however, may not be indicative of the population as a whole. It may, however, be argued that there are similar socioeconomic and cultural backgrounds among the participants.

The utilize of numerous methodologies such as diagnosis, sample size, and recording procedures, 
Table 1 Risk of bias in the current study

\begin{tabular}{|c|c|c|c|c|c|c|c|c|c|c|c|}
\hline \multicolumn{11}{|c|}{ Risk of Bias Domains } & \multirow[b]{2}{*}{ Weight } \\
\hline & 1 & 2 & 3 & 4 & 5 & 6 & 7 & 8 & 9 & Overall & \\
\hline 1. & Umer \& Umer [19] & 1 & + & + & + & + & + & & + & + & 100 \\
\hline 2. & Tahir et al. [20] & & & & & & & & + & & 11.1 \\
\hline 3. & Shaikh et al. [21] & & + & & + & + & (+) & 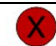 & + & - & 66.6 \\
\hline 4. & Ilyas et al. [22] & & + & d & & $\mathrm{X}$ & $\mathrm{X}$ & & + & - & 55.5 \\
\hline 5. & Ali et al. [23] & & + & & & + & 8 & & + & - & 77.7 \\
\hline 6. & Malik et al. [24] & & X & & & + & 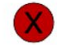 & & + & & 22.2 \\
\hline 7. & Umer et al. [25] & & $\mathrm{X}$ & $\sqrt{2}$ & & + & 8 & & + & 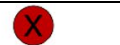 & 44.4 \\
\hline 8. & Dawani et al. [26] & & + & & & + & & & + & + & 100 \\
\hline 9. & Sahito et al. [27] & & & ( & & & 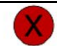 & & & & 11.1 \\
\hline 10. & Sufia et al. [28] & & + & & & + & + & & + & + & 100 \\
\hline 11. & Ahmed et al. [29] & & $X$ & & & $X$ & + & & + & - & 55.5 \\
\hline 12. & Sami et al. [30] & & + & & $x$ & + & 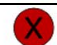 & & + & - & 77.7 \\
\hline 13. & Masoud et al. [31] & & + & + & & + & 8 & & + & - & 66.6 \\
\hline 14. & Badar et al. [32] & & $x$ & & & + & 2 & & & & 11.1 \\
\hline 15. & Khan et al. [33] & & + & 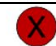 & 8 & + & 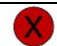 & 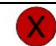 & 8 & & 22.2 \\
\hline 16. & Leghari et al. [34] & & + & + & 7 & + & 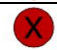 & 8 & + & & 44.4 \\
\hline 17. & Mohiuddin et al. [35] & & + & + & & $\mathrm{X}$ & $\vec{c}$ & & + & - & 77.7 \\
\hline 18. & Mirza et al. [36] & & + & 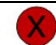 & & + & 8 & 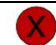 & 8 & & 22.2 \\
\hline 19. & Mirza et al. [37] & & + & & & + & 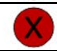 & ( & + & & 44.4 \\
\hline 20. & Rafiq et al. [38] & & + & & & & & & & & 22.2 \\
\hline 21. & Jawed et al. [39] & & $x$ & (- & & & C & (c) & + & - & 77.7 \\
\hline 22. & Fatima javed. [40] & & + & 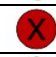 & & & 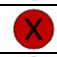 & 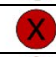 & + & 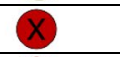 & 22.2 \\
\hline 23. & Umm-E-Aiman et al. [41] & & + & & & & & & + & & 33.3 \\
\hline 24. & Baloch et al. [42] & & + & 6 & + & + & & 7 & + & 7 & 88.8 \\
\hline 25. & Mehmood et al. [43] & & + & 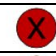 & & + & 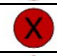 & 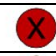 & + & 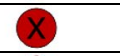 & 33.3 \\
\hline 26. & Rashid et al. [44] & & + & 7 & & & & & + & & 22.2 \\
\hline 27. & Nayani et al. [45] & & + & 7 & + & + & ( & + & + & F) & 88.8 \\
\hline 28. & Kamran et al. [46] & & + & + & + & + & + & + & + & + & 100 \\
\hline 29. & Khan et al. [47] & & + & $\bar{C}$ & X & & $\mathrm{X}$ & & + & 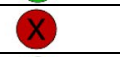 & 22.2 \\
\hline 30. & Taqi et al. [48] & & & + & + & & + & + & + & + & 88.8 \\
\hline & $\begin{array}{l}\quad \text { Risk of Bias Legend } \\
\text { 1.Bias arising from the sample frame } \\
\text { 2.Bias arising from inappropriate sampling } \\
\text { 3.Bias from a sample size } \\
\text { 4.Bias due to study subjects and setting } \\
\text { 5.Bias due to analysis conducted with insufficient } \\
\text { coverage of the identified sample } \\
\text { 6.Bias due to methods used for the identification } \\
\text { condition } \\
\text { 7.Bias in the reliability of the measurement of the } \\
\text { condition } \\
\text { 8.Bias during statistical analysis } \\
\text { 9.Bias arising from response rate adequate }\end{array}$ & & & & & & & & & $\begin{array}{l}\text { Low } \\
\text { Moder } \\
\text { High }\end{array}$ & \\
\hline
\end{tabular}




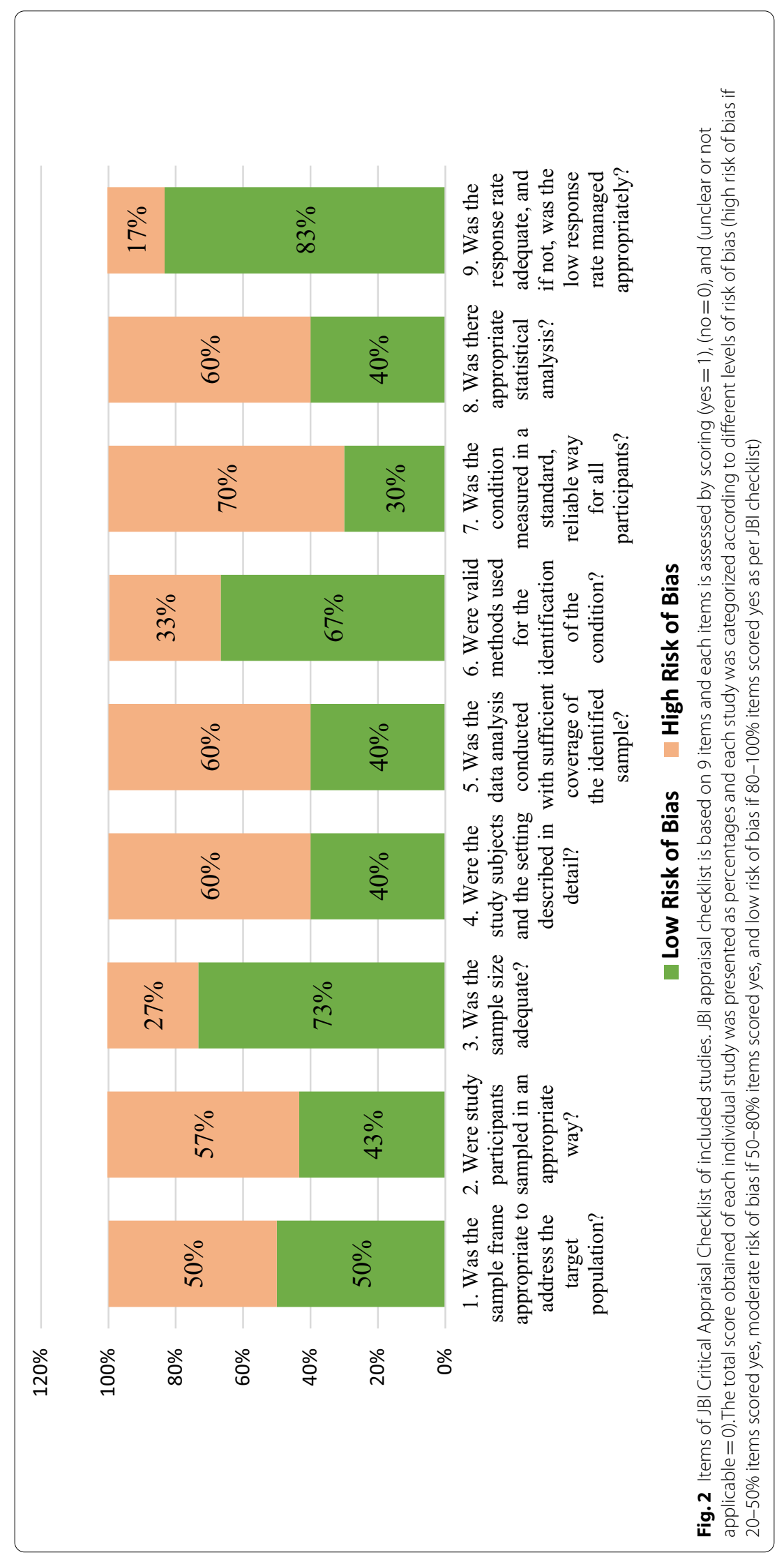


Table 2 The characteristics of included studies in meta-analysis

\begin{tabular}{|c|c|c|c|c|c|c|c|}
\hline Authors & Year & $\begin{array}{l}\text { Age group } \\
\text { (Years) }\end{array}$ & City/ Province & Type of dentition & $\begin{array}{l}\text { Method of Caries } \\
\text { diagnosis }\end{array}$ & $\begin{array}{l}\text { Sample size } \\
\text { (n) } \\
\text { No. of } \\
\text { people } \\
\text { examined }\end{array}$ & $\begin{array}{l}\text { Prevalence of } \\
\text { dental caries } \\
\text { (n) }\end{array}$ \\
\hline Umer and Umer [19] & 2011 & $8-10$ years & Peshawar/KPK & Mixed dentition & WHO criteria & 500 & 362 \\
\hline Tahir et al. [20] & 2015 & $5-12$ years & Multan/Punjab & Mixed dentition & Not reported & 152 & 94 \\
\hline Shaikh et al. [21] & 2014 & $9-18$ years & Khairpur/Sindh & Permanent Dentition & WHO criteria & 406 & 57 \\
\hline Ilyas et al. [22] & 2015 & Not reported & Hyderabad/Sindh & - & WHO criteria & 278 & 168 \\
\hline Ali et al. [23] & 2012 & $5-14$ years & Lahore/Punjab & Mix dentition & WHO criteria & 1673 & 1188 \\
\hline Malik et al. [24] & 2014 & Not reported & Karachi/ Sindh & Permanent Dentition & $\begin{array}{l}\text { Caries Assessment } \\
\text { Spectrum and } \\
\text { treatment(CAST),third } \\
\text { molars were not } \\
\text { included }\end{array}$ & 100 & 8 \\
\hline Umer et al. [25] & 2016 & $3-12$ years & Sargodha/Punjab & Mix dentition & Presence of Frank Cavity & 518 & 238 \\
\hline Dawani et al. [26] & 2012 & $3-6$ years & Karachi/Sindh & Primary dentition & WHO criteria & 1000 & 510 \\
\hline Sahito et al. [27] & 2015 & $8-12$ year & Hyderabad/Sindh & Mix dentition & Not reported & 100 & 90 \\
\hline Sufia et al. [28] & 2011 & $3-5$ Years & Lahore/Punjab & Primary dentition & WHO criteria & 601 & 243 \\
\hline Ahmed et al. [29] & 2017 & $6-12$ years & Hyderabad/Sindh & Mix dentition & WHO criteria & 395 & 196 \\
\hline Sami et al. [30] & 2016 & 12 years & Quetta/Baluchistan & Permanent dentition & WHO criteria & 349 & 81 \\
\hline Masoud et al. [31] & 2020 & $3-5$ years & Islamabad & Primary dentition & WHO criteria & 384 & 189 \\
\hline Badar et al. [32] & 2012 & $11-70$ years & Bahawalpur/Punjab & Permanent dentition & Not reported & 400 & 388 \\
\hline Khan et al. [33] & 2019 & 12 years and above & Islamabad & Permanent dentition & Not reported & 349 & 312 \\
\hline Leghari et al. [34] & 2014 & 15 years & Karachi/Sindh & Permanent dentition & WHO criteria & 392 & 274 \\
\hline Mohiuddin et al. [35] & 2015 & 6 and 12 years & Karachi/Sindh & Mix dentition & WHO criteria & 1600 & 1114 \\
\hline Mirza et al. [36] & 2017 & 2-19 years & Lahore/Punjab & Mix dentition & WHO criteria & 12,971 & 7409 \\
\hline Mirza et al. [37] & 2013 & $3-8$ years & Lahore/ Punjab & Primary dentition & WHO criteria & 642 & 391 \\
\hline Rafiq et al. [38] & 2019 & 20-80 years & Karachi/Sindh & Permanent dentition & $\begin{array}{l}\text { Clinical assessment of } \\
\text { dental caries done by } \\
\text { DMFT }\end{array}$ & 377 & 370 \\
\hline Jawed et al. [39] & 2020 & $6-18$ years & Karachi/Sindh & Mix dentition & WHO criteria & 196 & 114 \\
\hline Fatima javed. [40] & 2019 & $18-29$ years & Faisalabad/Punjab & Permanent dentition & Not reported & 571 & 74 \\
\hline $\begin{array}{l}\text { Umm-E-Aiman et al. } \\
\text { [41] }\end{array}$ & 2018 & $\begin{array}{l}6,12 \text { and } 15 \text { years } \\
\text { age }\end{array}$ & Multan/Punjab & Mix dentition & WHO criteria & 500 & 320 \\
\hline Baloch et al. [42] & 2009 & 12 years old & Quetta/Baluchistan & Permanent dentition & Not reported & 153 & 124 \\
\hline Mehmood et al. [43] & 2017 & $5-6$ years & Rawalpindi/Punjab & Primary dentition & WHO criteria & 384 & 195 \\
\hline Rashid et al. [44] & 2016 & Not reported & Sialkot/Punjab & - & WHO criteria & 1008 & 447 \\
\hline Nayani et al. [45] & 2018 & $5-14$ years & Karachi/Sindh & Mix dentition & $\begin{array}{l}\text { Dental examination was } \\
\text { done indoor by using } \\
\text { small wooden spatula } \\
\text { and a common hand } \\
\text { torch light. Wooden } \\
\text { spatula was used to } \\
\text { retract the tongue and } \\
\text { cheeks }\end{array}$ & 500 & 336 \\
\hline Kamran et al. [46] & 2017 & 4-17 years & Rawalpindi/Punjab & Mix dentition & WHO criteria & 753 & 262 \\
\hline Khan et al. [47] & 2017 & $12-17$ & Peshawar/KPK & Permanent dentition & Not reported & 400 & 110 \\
\hline Taqi et al. [48] & 2018 & $11-12$ years & Bhakkar/Punjab & Mix dentition & $\begin{array}{l}\text { International Caries } \\
\text { Detection and Assess- } \\
\text { ment System ICDAS }\end{array}$ & 226 & 115 \\
\hline
\end{tabular}

randomization, and form of study was another potential weakness that is typical in dental caries studies. Heterogeneity and publication bias are other inevitable shortcomings of most meta-analysis research, which was also evident in the current meta-analysis. We used Cochran's $Q$ test $\left(X^{2}\right)$ and the $I^{2}$ statistic for verifications: the funnel plots showed asymmetrical shape at the bottom in prevalence studies indicating the presence of publication 
Table 3 Summary of included studies with variables and prevalence estimate of dental caries in Pakistan

\begin{tabular}{|c|c|c|c|c|c|}
\hline \multirow[t]{2}{*}{ Study } & \multirow[t]{2}{*}{ Sample size } & \multirow[t]{2}{*}{ Proportion (\%) } & \multirow[t]{2}{*}{$95 \% \mathrm{Cl}$} & \multicolumn{2}{|c|}{ Weight (\%) } \\
\hline & & & & Fixed & Random \\
\hline Umer and Umer [19] & 500 & 72.400 & 68.257 to 76.276 & 1.80 & 3.35 \\
\hline Tahir et al. [20] & 152 & 61.842 & 53.620 to 69.593 & 0.55 & 3.26 \\
\hline Shaikh et al. [21] & 406 & 14.039 & 10.810 to 17.804 & 1.46 & 3.34 \\
\hline Ilyas et al. [22] & 278 & 60.432 & 54.417 to 66.221 & 1.00 & 3.32 \\
\hline Ali et al. [23] & 1673 & 71.010 & 68.771 to 73.176 & 6.00 & 3.38 \\
\hline Malik et al. [24] & 100 & 8.000 & 3.517 to 15.156 & 0.36 & 3.19 \\
\hline Umer et al. [25] & 518 & 45.946 & 41.592 to 50.347 & 1.86 & 3.36 \\
\hline Dawani et al. [26] & 1000 & 51.000 & 47.853 to 54.142 & 3.59 & 3.38 \\
\hline Sahito et al. [27] & 100 & 90.000 & 82.378 to 95.100 & 0.36 & 3.19 \\
\hline Sufia et al. [28] & 601 & 40.433 & 36.481 to 44.478 & 2.16 & 3.36 \\
\hline Ahmed et al. [29] & 395 & 49.620 & 44.582 to 54.664 & 1.42 & 3.34 \\
\hline Sami et al. [30] & 349 & 23.209 & 18.881 to 27.999 & 1.25 & 3.34 \\
\hline Masoud et al. [31] & 384 & 49.219 & 44.111 to 54.339 & 1.38 & 3.34 \\
\hline Badar et al. [32] & 400 & 97.000 & 94.818 to 98.440 & 1.44 & 3.34 \\
\hline Khan et al. [33] & 349 & 89.398 & 85.684 to 92.425 & 1.25 & 3.34 \\
\hline Leghari et al. [34] & 392 & 69.898 & 65.091 to 74.401 & 1.41 & 3.34 \\
\hline Mohiuddin et al. [35] & 1600 & 69.625 & 67.306 to 71.872 & 5.74 & 3.38 \\
\hline Mirza et al. [36] & 12,971 & 57.120 & 56.263 to 57.974 & 46.48 & 3.40 \\
\hline Mirza et al. [37] & 642 & 60.903 & 57.008 to 64.698 & 2.30 & 3.36 \\
\hline Rafiq et al. [38] & 377 & 98.143 & 96.212 to 99.250 & 1.35 & 3.34 \\
\hline Jawed et al. [39] & 196 & 58.163 & 50.922 to 65.153 & 0.71 & 3.29 \\
\hline Fatima javed. [40] & 571 & 12.960 & 10.315 to 15.995 & 2.05 & 3.36 \\
\hline Umm-E-Aiman et al. [41] & 500 & 64.000 & 59.620 to 68.214 & 1.80 & 3.35 \\
\hline Baloch et al. [42] & 153 & 81.046 & 73.926 to 86.923 & 0.55 & 3.26 \\
\hline Mehmood et al. [43] & 384 & 50.781 & 45.661 to 55.889 & 1.38 & 3.34 \\
\hline Rashid et al. [44] & 1008 & 44.345 & 41.249 to 47.474 & 3.62 & 3.38 \\
\hline Nayani et al. [45] & 500 & 67.200 & 62.892 to 71.303 & 1.80 & 3.35 \\
\hline Kamran et al. [46] & 753 & 34.794 & 31.391 to 38.317 & 2.70 & 3.37 \\
\hline Khan et al. [47] & 400 & 27.500 & 23.180 to 32.157 & 1.44 & 3.34 \\
\hline Taqi et al. [48] & 226 & 50.885 & 44.172 to 57.575 & 0.81 & 3.30 \\
\hline Total (fixed effects) & 27,878 & 56.999 & 56.415 to 57.581 & 100.00 & 100.00 \\
\hline Total (random effects) & 27,878 & 56.625 & 49.546 to 63.571 & 100.00 & 100.00 \\
\hline
\end{tabular}

Q statistics $=3342.9702, \mathrm{DF}=29, P<0.001, \mathrm{I}^{2}=99.13$ (99.02 to 99.23$)$

bias, which was confirmed by the insignificant result of Cochran's $Q$ test $\left(\chi^{2}\right)$ and the $\mathrm{I}^{2}$ statistic.

By visual inspection of the forest plot, heterogeneity can be estimated. Where there is a low correlation in confidence intervals for the outcomes of individual studies, this usually indicates the existence of statistical heterogeneity [49]. Therefore, we used a random-effects model for the calculation of proportion estimate of dental caries, While the confidence interval quantifies the precision of the point estimate, the true dispersion of effect sizes is discussed by the prediction interval. Two problems are unique and not synonymous. Therefore, we should also estimate the prediction interval if we use a random-effects model to make inferences that are more insightful in meta-analyses [50].

DMFT index is the most used index for the measurement of dental caries at the population level. According to Castro et al. [51], most of the study participants thought to use some other index yet continued to use it as according to them, they could not found a more reliable method of measurement of dental caries. Almost all indices have limitations. To date, DMFT is a widely used and accepted method of measuring dental caries at the community level. It can only detect cavitated lesions and cannot account for incidence [52]. 


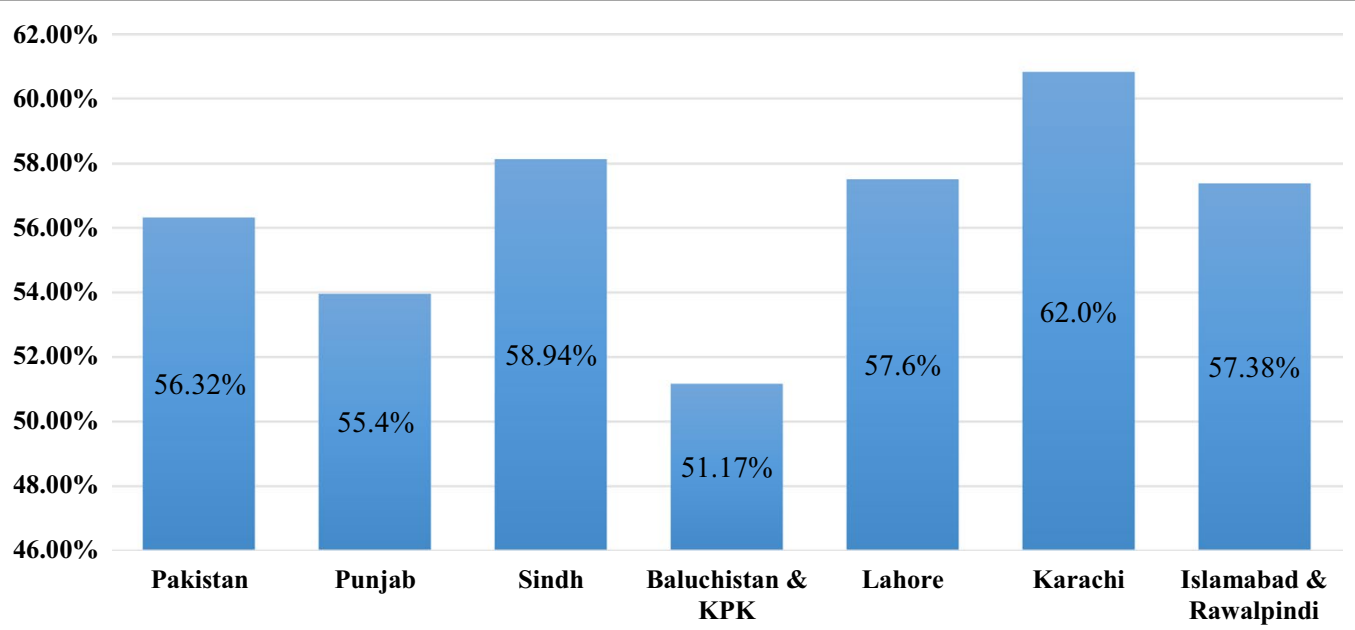

Fig. 3 Prevalence estimate of dental caries in provinces and cities of Pakistan. The prevalence estimate (random effect model) of dental caries in Punjab was 53.95\%, in Sindh 58.135\% while in Baluchistan and KPK combined was 51.17\% The prevalence estimate of dental caries in major cities of the countries was as following: Karachi $60.83 \%$, Lahore $57.51 \%$, while Islamabad and Rawalpindi combined was $57.38 \%$

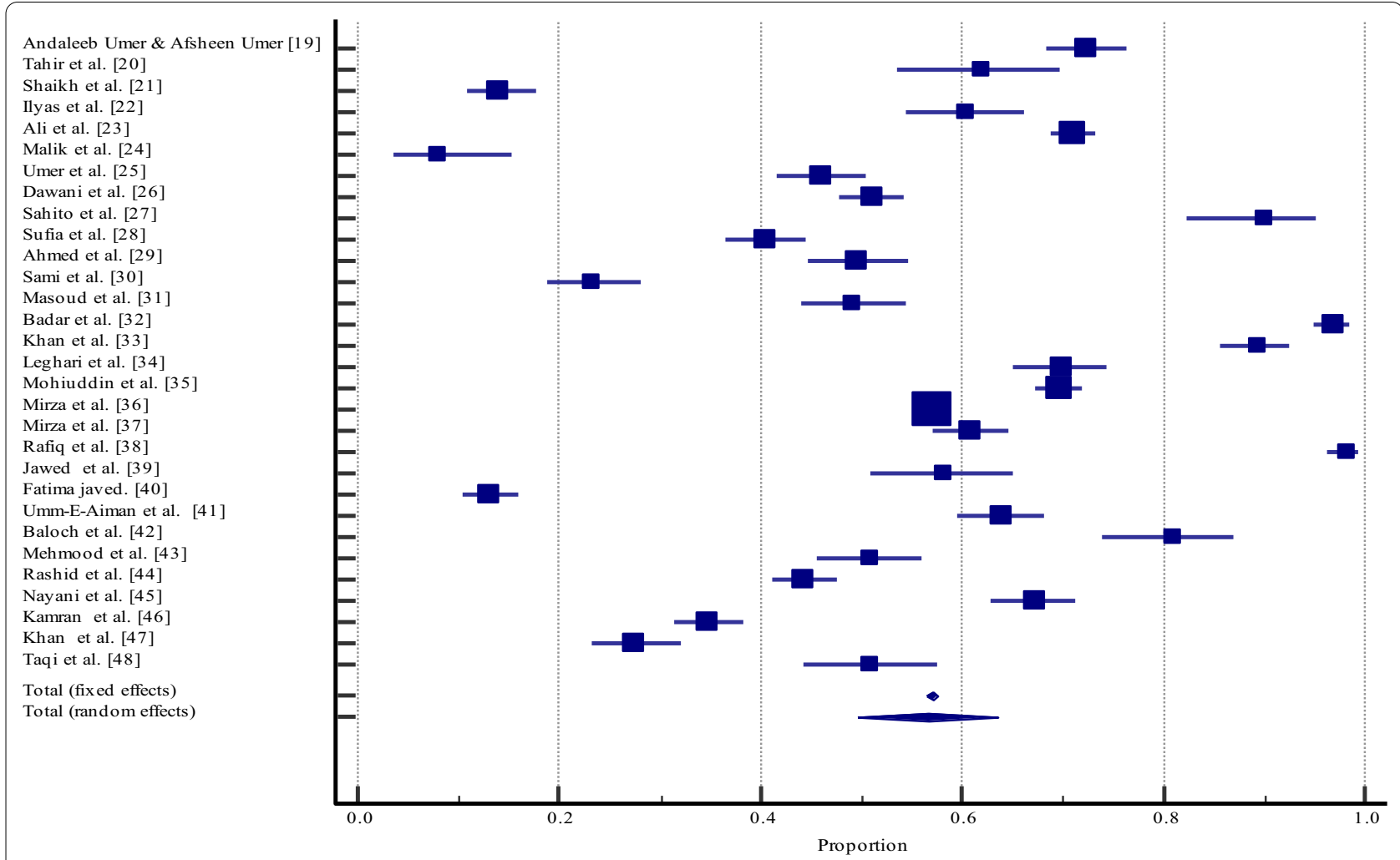

Fig. 4 Forest plot showing effect of different studies and overall effect at 95\% Cl regarding dental caries from (2009-2020). Forest plot is displaying the proportion prevalence of dental caries of each study included in meta-analysis. The highest prevalence of dental caries was reported by Badar et al. in Bahawalpur while lowest was reported by Malik et al. in Karachi

The overall quality of evidence in the selected studies was classified as moderate, with the majority of the studies achieving a moderate risk of bias. Seven studies were found to have low risk. In the present meta-analysis study, the prevalence of dental caries in primary, mixed and permanent teeth studied in this study. In the primary dentition, the prevalence of caries was 50.493\%, and mixed dentition was $61.183 \%$, whereas it was around 


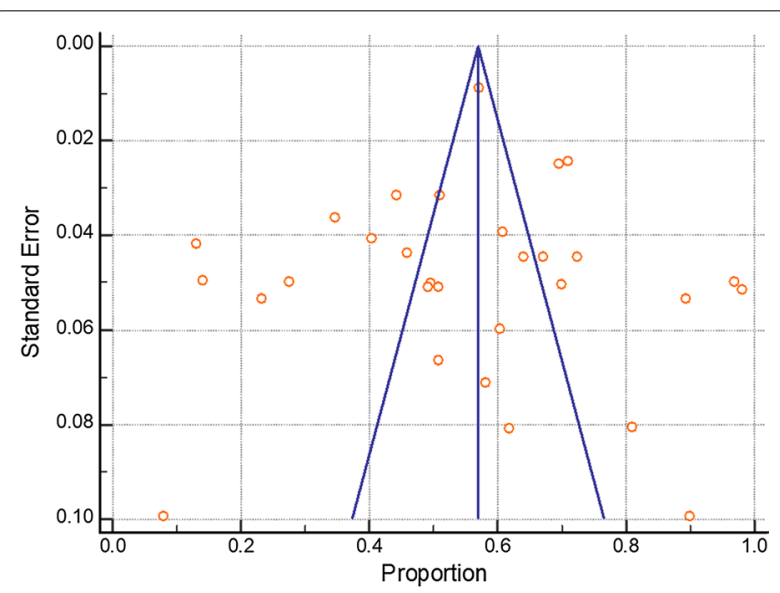

Fig. 5 Funnel plot showing prevalence of dental caries as proportion. The funnel plot shows the effect estimates of the included studies against their measure of precision or size of the studies. The funnel plot is showing asymmetry that is indicating heterogeneity and reporting bias

$57.184 \%$ of the permeant dentition. During the start of 1980s The World Health Organization alongside FDI World dental federation formulated goals to control the spread of dental caries and mentioned that $50 \%$ of children between the ages of 5 and 6 should be free of dental caries by the year 2000 [53]. However, till date in most countries, the prevalence of dental caries in children reported to be very high. This situation creates troubling conditions for tooth decay in adulthood and would also place enormous costs for tooth restoration on the health sector in the country. The overall prevalence estimate of the proportion of dental caries (random effect model) was $56.32 \%$. The identified factors for dental caries are poor oral hygiene habits, intake of cariogenic diet, and low socioeconomic status [54]. The above findings demonstrated high levels of both prevalence and severity in terms of caries. In various included studies, the prevalence of dental caries was reported to be varied. This is in agreement with the finding of Richardson et al. [55] that reported the frequency of dental caries in various studies differs significantly, because of many factors, including (1) subjects studied; their age, and the accessibility for examination; (2) racial and cultural factors; (3) socioeconomic status; and (4) diagnostic criteria. Also, the prevalence of dental caries is typically incomparable with another in one region, so it is not possible to extrapolate findings from one ethnic group within that group [55].

As a result of many clinical studies and preventive initiatives focused on caries prevention, developed countries have less caries prevalence and a decrease in caries levels in contrast to countries with good oral health systems such as the Scandinavian countries, dental caries is still a continuing oral health issue [56]. There exists a continuous need of measuring the incidence/prevalence of dental caries. The findings of the 2013 Child Dental Health Survey in England, Wales, and Northern Ireland showed that the prevalence of caries was $31 \%$ in five-year-old kids [57]. Treatment needs for dental caries depend upon the changing pattern of a disease over time. A study from the United States reported that the prevalence of dental caries in school-going children was low since the 1960s, however, the incidence seems to be slightly increased from 24 to $28 \%$ during the late 1980 s to 2004 . [58]. That is why regular monitoring of disease prevalence's overtime is of essential importance. A study on 2214 Australian children aged 5 to 8 years reported the prevalence of dental caries to be lower than the current pooled prevalence of $56.32 \%$ [59].

Generally, the prevalence of dental caries in the current study was $56.32 \%$. There were high differences within the included studies with the lowest of $8 \%$ stated by Malik et al. [24] and the highest of $97 \%$ exhibited by Badar et al. [32]. A generally low level of reported prevalence can be because of widespread usage of fluoridated toothpaste [60] and the introduction of a national oral health program [61]. Other probable reasons for such variance can be due to the various geographical areas, the variations between the individuals included in the analysis, and sample size. Oral health policies, fluoridation of community water, and oral hygiene products often play a role in the variability between countries [62]. In most provinces of Pakistan, low levels of water fluoridation were observed, likewise, only 22 percent of the Libyan population receives fluoridated water [63]. Consumption of foods containing sugar is high and easily available everywhere like schools, offices in Pakistan which can be one of the probable causative factors for a higher rate of dental caries in the country.

Some remarkable points were noted during the quality evaluation, which should be considered for future studies by researchers. More specifically, the occurrence of caries in deciduous and permanent dentition should be reported separately. Along with the mean prevalence of the age groups included in the report, the prevalence of caries for individual ages should also be indicated.

The present meta-analysis found studies with certain methodological flaws such as sampling technique, sample size. Besides that, we also noticed a strong publication bias. Another probable limitation observed was the geographical distribution of studies that contain data on prevalence was mainly reported from larger cities of the country. A substantial region of Pakistan is still unexposed, and there still can be an unexplained prevalence of dental caries. It could therefore be assumed that the findings obtained could not present an accurate picture of the 
prevalence of dental caries in Pakistan. There is a need for national-level population-based studies with equal representation from urban and rural areas of the country. In addition, future epidemiological studies should be conducted to explore various determinant factors of dental caries in the countries. It will help the policymaker in managing the burden of dental caries in the Pakistani population.

\section{Conclusions}

Within the limitations of this study, it can be concluded that in Pakistan dental caries is a serious dental public health issue. Dental caries in Pakistan was found to be approximately $60 \%$. Most of the studies on dental caries are of poor quality and contain a high amount of bias. To get a precise image of the prevalence of dental caries amongst subjects in the area, additional studies documenting dental caries from all cities are needed.

Therefore, in Pakistan, the level of dental caries should be a priority, and oral health care investment should be devoted to the preparation of oral health policies and programs. That will enhance the oral health-related quality of life of this demographic part.

\section{Abbreviations}

WHO: World Health Organization; Cl: Confidence interval; JBI: Joanna Briggs Institute; KPK: Khyber Pakhtunkhwa.

\section{Supplementary Information}

The online version contains supplementary material available at https://doi. org/10.1186/s12903-021-01802-x.

\section{Additional file 1. Table S1: Prevelence of dental caries in primary} dentition.

Additional file 2. Table S2: Prevelence of dental caries in mixed dentition. Additional file 3. Table S3: Prevelence of dental caries in permanent dentition.

Additional file 4. Table S4: Forest plot for subgroup analysis.

Additional file 5. Table S5: Funnel plot for subgroup analysis.

\section{Acknowledgements}

Not applicable.

\section{Authors' contributions}

AAS contributed to the research concept, study design, data collection, statistical analysis, writing the original draft, and reviewing and editing the final manuscript. FA and MM contributed to the research concept, study design, and writing and reviewing the original draft. SMA and AAM contributed to research concept, study design, statistical analysis, and writing and reviewing the original draft. EA, JA, SA, SS, and MKA contributed to the writing and reviewing of the original draft. The final version of the manuscript was read and approved by every author. All authors read and approved the final manuscript.

\section{Funding}

None.
Availability of data and materials

All data analyzed during this study are included in this manuscript.

\section{Declarations}

Ethics approval and consent to participate

Not applicable.

\section{Consent for publication}

Not applicable.

\section{Competing interests}

The authors declare that they have no competing interests.

\section{Author details}

${ }^{1}$ Department of Community Dentistry, College of Dentistry, Bakhtawar Amin Medical and Dental College, Multan, Pakistan. ${ }^{2}$ Present Address: Department of Preventive Dentistry, College of Dentistry, University of Ha'il, Hail, Saudi Arabia. ${ }^{3}$ Department of Oral and Dental Health, College of Applied Health Sciences Arrass, Qassim University, Qassim, Saudi Arabia. ${ }^{4}$ Department of Restorative Dental Sciences, College of Dentistry, University of Ha'il, Hail, Saudi Arabia. ${ }^{5}$ General Dental Practitioner, Private Clinic, Islamabad, Pakistan. ${ }^{6}$ College of Applied Medical Sciences, University of Ha'il, Hail, Saudi Arabia. ${ }^{7}$ College of Medicine and Dentistry, University of Lahore, Lahore, Pakistan. ${ }^{8}$ Department of Oral Diagnostics, College of Dentistry, University of Ha'il, Hail, Saudi Arabia. ${ }^{9}$ Department of Preventive Dentistry, College of Dentistry, Jouf University, Aljouf, Saudi Arabia.

Received: 24 November 2020 Accepted: 1 September 2021 Published online: 16 September 2021

\section{References}

1. Saunders SR, De Vito C, Katzenberg MA. Dental caries in nineteenth century upper Canada. Am J Phys Anthropol. 1997;104:71-87.

2. Griffin SO, Gray SK, Dolores MM, Gooch BF. Caries risk in formerly sealed teeth. J Am Dent Assoc. 2009;140:415-23.

3. Dye BA, Tan S, Smith V, Lewis BG, Barker LK, Thornton-Evans G, et al. Trends in oral health status: United States, 1988-1994 and 1999-2004. Vital Health Stat. 2007;11(11):1-92.

4. Shivakumar K, Vidya S, Chandu G. Dental caries vaccine. Indian J Dent Res. 2009;20(1):99-106.

5. Petersen PE. Continuous improvement of oral health in the 21 st century - the approach of the WHO Global Oral Health Programme. Geneva: World Health Organization; 2003 (https://www.who.int/oral_health/ media/en/orh_report03_en.pdf, accessed 20 December 2019).

6. Almeida-Filho N. For a general theory of health: preliminary epistemological and anthropological notes. Cad. Saude Publica. 2001;17(4):753-70.

7. Lee Y. Diagnosis and prevention strategies for dental caries. J Lifestyle Med. 2013;3(2):107-9.

8. Selwitz HR, Ismail A, Pitts BN. Dental caries. Lancet. 2007;369(9555):51-9.

9. Marsh PD. Are dental diseases examples of ecological catastrophes? Microbiology. 2003;149(2):279-94.

10. Kassebaum N, Bernabé E, Dahiya M, Bhandari B, Murray C, Marcenes W. Global burden of untreated caries: a systematic review and metaregression. J Dent Res. 2015;94(5):650-8.

11. Petersen PE, Kandelman D, Arpin S, Ogawa H. Global oral health of older people-call for public health action. Community Dent Health. 2010;27(4):257-67.

12. Madanlou M, Khosravi H, Ghobadi K, Abdollahi H, Ziaie T, Behnampour N. Oral health status of elderly in Gorgan City in 2006. J Gorgan Univ Med Sci. 2010;12(3):68-73.

13. Emami E, de Souza RF, Kabawat M, Feine JS. The impact of edentulism on oral and general health. Int J Dent. 2013;2013: Article ID 498305.

14. Starr JM, Hall RJ, Macintyre S, Deary IJ, Whalley LJ. Predictors and correlates of edentulism in the healthy old people in Edinburgh (HOPE) study. Gerodontology. 2008;25(4):199-204.

15. da Silva Araújo AC, Gusmão ES, Batista JEM, Cimões R. Impact of periodontal disease on quality of life. Quintessence Int. 2010:41(6):e111-8. 
16. Al Agili DE. A systematic review of population-based dental caries studies among children in Saudi Arabia. Saudi Dent J. 2013;25(1):3-11.

17. Fact sheets: oral health [website]. Geneva: World Health Organization (https://www.who.int/news-room/fact-sheets/detail/oral-health, accessed 20 December 2018).

18. Munn Z, Moola S, Lisy K, Riitano D, Tufanaru C. Methodological guidance for systematic reviews of observational epidemiological studies reporting prevalence and cumulative incidence data. Int J Evid Based Healthc. 2015:13(3):147-53.

19. Umer A, Umer A. Prevalence of dental caries among the primary school children of urban Peshawar. J Khyber Coll Dent. 2011;2(1):1-6.

20. Tahir A, Jahangir $R$, Ahad A. Determinants of dental caries in primary school going children of Multan. Pak J Med Health Sci. 2017;1 1(4):1485-8.

21. Shaikh I, Kalhoro F, Pirzado M, Memon A, sahito M, Dahri W, Malhi P. Prevalence of dental caries among students of khairpur district. Pak Oral Dental J. 2014; 34(4): 680-3.

22. Ilyas M, Memon AB, Khatoon S, Kumar S, Afridi AK, Mallah AH. Dental caries among the patients visiting outpatient department of liaquat medical university hospital, Hyderabad" Sindh. Pak Oral Dental J. 2015;35(3):472-5.

23. Ali S, Bhatti MUD, Syed A, Chaudhry AH, lqbal Z. Prevalence of dental caries among 5-14 years old poor locality school children of Lahore. Pak Oral Dental J. 2012;32(2):279-82.

24. Malik A, Shaukat MS, Qureshi A. Prevalence of dental caries using novel caries assessment index-CAST. J Dow Univ Health Sci. 2014;8(1):7-10.

25. Umer MF, Farooq U, Shabbir A, Zofeen S, Mujtaba H, Tahir M. Prevalence and associated factors of dental caries, gingivitis, and calculus deposits in school children of sargodha district, pakistan. J Ayub Med Coll Abbottabad. 2016;28(1):152-6.

26. Dawani N, Nisar N, Khan N, Syed S, Tanweer N. Prevalence and factors related to dental caries among pre-school children of Saddar town, Karachi, Pakistan: a cross-sectional study. BMC Oral Health. 2012;12(1):59.

27. Sahito N, Sahito MA, Fazlani KA. Prevalence of dental caries among school children in Hyderabad Pakistan. Int J Appl Sci Res Rev. 2015;26:34-8.

28. Sufia S, Chaudhry S, Izhar F, Syed A, Qayum Mirza BA, Ali KA. Dental caries experience in preschool children: is it related to a child's place of residence and family income? Oral Health Prev Dent. 2011;9(4):375-9.

29. Ahmed W, Manzoor F, Khayyam U. Dental caries status among public and private School Children In Hyderabad District-Sindh. Pak Oral Dental J. 2017;37(2):309-12

30. Sami E, Vichayanrat T, Satitvipawee P. Caries with dental fluorosis and oral health behaviour among 12-year school children in moderate-fluoride drinking water community in Quetta, Pakistan. J Coll Physicians Surg Pak. 2016;26(9):744-7.

31. Masoud S, Qazi SH, Mumtaz R. Prevalence of dental caries and its association with risk factors amongst preschool children of Bharakahu, Islamabad. J Islamabad Med Dent College. 2020:9(2):88-94.

32. Badar S, Channar S, Bhutta N, Arshad S. Dental caries. Professional Med J. 2012;19(01):117-22.

33. Khan ZA, Qureshi B, Anwer U, Asghar SK, Fatima K. Frequency of associated factors causing dental caries in patients reporting at tertiary care hospital. J Pak Dent Assoc. 2019;28(3):118-21.

34. Leghari MA, Tanwir F, Ali H. Association of dental caries and parents knowledge of oral health, a cross-sectional survey of schools of Karachi. Pakistan J Pak Dent Assoc. 2014;23(01):19-24.

35. Mohiuddin S, Nisar N, Dawani N. Dental caries status among 6 and 12 years old school children of Karachi city. J Pak Dent Assoc. 2015;24(1):39-45.

36. Mirza BA, Shakoor A, Anwaar A, Zahra FT. Prevalence of dental caries in garrison schools of Lahore. Pak Oral Dent J. 2017:37(1):133-6.

37. Mirza BA, Chohan AN, Sajid M, Kahlown RA. Dental caries prevalence in 3-8 year old children of army schools in Lahore. Pak Oral Dent J. 2013;33(2):364-6.

38. Rafiq M, Hasan R, Bano M. Prevalence of dental caries and periodontal disease among elderly patients attending private dental college karachi: a hospital based cross sectional study. Pak Oral Dent J. 2018;38(4):500-2.

39. Jawed R, Khan Z, Kibria Z, Ahmad F. Dental caries and its determinants among children with special health care needs in district. Karachi, Pakistan. Khyber Med Univ J. 2020;12(1):19-24

40. Javed F. Prevalence and severity of dental caries among patients in Pakistan: a correlation of age, gender and tooth number. Indo Am J Pharm. 2009;06(03):6782-5.
41. Umm-E-Aiman, Zaib MU, ul Ain, Qurat, Hina S, Saleem MR. A cross sectional study on the incidence of dental caries in the school going children of Multan. Indo Am J Pharm. 2018 May 1:5(5):3412-6.

42. Baloch HN, Baloch M-U-R, Mengal N, Saeed M, Khan NF, Ahmed J, Prevalence of dental caries among 12 years old school children in Quetta, Balochistan. Med Forum 2009; 20: 31-5.

43. Mehmood B, Faisal MR, Hassan F, Afzal E. Treated and untreated dental caries status and its co-variates in 5-6 years old children in rawalpindi-a pilot study. Pak Oral Dent J. 2017:37(1):148-51.

44. Rashid S, Rizwan M, Khan RMS, Hasan KR. Prevalence of dental caries among the patients visiting Islam Dental College Hospital Sialkot. Med Forum Mon. 2016:1(27):10-2.

45. Nayani AA, labal R, Azam SI, Khan FR, Khan AH, Janjua N, Hussain A. Association between environmental tobacco smoke and dental caries amongst 5-14 years old children in Karachi. Pakistan J Pak Med Assoc. 2018;68(2):203-9.

46. Kamran R, Farooq W, Faisal MR, Jahangir F. Clinical consequences of untreated dental caries assessed using PUFA index and its covariates in children residing in orphanages of Pakistan. BMC Oral Health. 2017;17(1):1-7.

47. Khan AH, Ahad B, Amanat U, Khan KH, Hassan D. Dental health self-care among school going children of peshawar. J Med Sci. 2017;25(4):398-402.

48. Taqi M, Razak IA, Ab-Murat N. Sugar consumption and caries occurrence among Pakistani school children. J Pak Med Assoc. 2018;68(10):1483-7.

49. Higgins JP, Thompson SG, Deeks JJ, Altman DG. Measuring inconsistency in meta-analyses. BMJ. 2003;327(7414):557-60.

50. IntHout J, loannidis JP, Rovers MM, Goeman JJ. Plea for routinely presenting prediction intervals in meta-analysis. BMJ Open. 2016 Jul;6(7):e010247.

51. Castro ALS, Vianna MIP, Mendes CMC. The knowledge and use of population-based methods for caries detection. BMC Oral Health. 2018;18(1):153.

52. WHO. Oral Health Surveys: Basic Methods. 4th ed. Geneva: World Health Organization; 1997.

53. WHO. Oral Health Information Systems. [Last accessed on 2017 Mar 17]. Available from: http://www.who.int/oral_health/action/information/surve illance/en/

54. Alhabdan YA, Albeshr AG, Yenugadhati $N$, Jradi H. Prevalence of dental caries and associated factors among primary school children: a population-based cross-sectional study in Riyadh, Saudi Arabia. Environ Health Prev Med. 2018;23(1):1-4.

55. Richardson B, Cleaton-Jones P, Mclnnes P, Rantsho J. Infant feeding practices and nursing bottle caries. ASDC J Dent Child Nov-Dec. 1981;48(6):423-9.

56. Haugejorden $\mathrm{O}$, Birkeland J. Evidence for reversal of the caries decline among Norwegian children. Int J Pediatr Dent. 2002;12(5):306-15.

57. Holmes R, Porter J, Vernazza C, Tsakos G, Ryan R, Dennes M. Health and Social Care Information Center; 2015. Child Dental Health Survey 2013, England, Wales and Northern Ireland.

58. Dye BA, Thornton-Evans G, Li X, lafolla TJ. Dental caries and sealant prevalence in children and adolescents in the United States, 2011-2012: US Department of Health and Human Services, Centers for Disease Control and Prevention, National Center for Health Statistics; 2015.

59. Do LG, Ha DH, Spencer AJ. Factors attributable for the prevalence of dental caries in Queensland children. Commun Dent Oral Epidemiol. 2015;43(5):397-405

60. El-Qaderi SS, Quteish Ta'ani D. Dental plaque, caries prevalence and gingival conditions of 14-15-year-old schoolchildren in Jerash District, Jordan. Int J Dent Hyg. 2006 Aug;4(3):150-3.

61. Saied-Moallemi Z, Virtanen Jl, Tehranchi A, Murtomaa H. Disparities in oral health of children in Tehran. Iran Eur Arch Paediatr Dent. 2006;7(4):262-4.

62. Alshammary F, Siddiqui AA, Al-Enizy AS, Almalaq SAS, Amin J, Rathore HA et al. Prevalence of dental fluorosis in Saudi Arabia: a meta-analysis. Pesqui Bras Odontopediatria Clín Integr. 2020; 20:e0105.

63. Cochrane $\mathrm{N}$, Poureslami H. Necessity of water fluoridation in Iran: A review on water fluoridation and prevention of dental caries. J Oral Epidemiol. 2014;3(1):1-7.

\section{Publisher's Note}

Springer Nature remains neutral with regard to jurisdictional claims in published maps and institutional affiliations. 